\title{
Integrated Device Electronic Untuk Sistem Irigasi Tetes Dengan Kendali Internet of Things
}

\author{
Angga Prasetyo ${ }^{1}$, Arief Rahman Yusuf ${ }^{2}$ \\ 1.2. Prodi Teknik Informatika Universitas Muhammadiyah Ponorogo jalan Budi Utomo 10 Ponorogo \\ 12angga_raspi@umpo.ac.id, ${ }^{2}$ aryusuf2589@gmail.com
}

\begin{abstract}
ABSTRAK.Semakin berkurangnya lahan perkotaan untuk bercocok tanam atau bertani membuat para kaum urban melakukan inovasi dengan memanfaatkan lahan sempit untuk meningkatkan pendapatan karena tuntutan kebutuhan ekonomi. Aktifitas bercocok tanam di lahan sempit membutuhkan perhatian dalam manajemen irigasi karena unsur kehidupan biji dan akar tanaman harus dijaga kelembapan pada kisaran 60\%.selama ini proses bercocok tanam dilahan sempit memiliki permasalahan yaitu pada proses irigasi. Hal ini dikarenakan para kaum urban memiliki lebih dari satu profesi pekerjaan serta mengalami kesulitan dalam membagi waktu. Sehingga proses irigasi dan penyiraman masih dilakukan secara manual. Agar proses irigasi tidak manual, maka dibutuhkan suatu pendekatan yang mampu menjembatani proses otomasi melibatkan sensor, hardware,perangkat lunak secara real time yaitu konsep teknologi yang memanfaatkan internet atau lebih dikenal internet of things (IoT). Pembuatan prototipe ini diawali dari rangkaian antara board nodeMcU esp8266 sebagai pusat kendali dan prosesing, kemudian relay terhubung GPIO pada output tersambung motor selenoid pompa dan catu daya. Selanjutnya sensor YL 69 dihubungkan pada GPIO dan catudaya 5V GPIOkemudian membuat aplikasi interface antar muka berbasis android untuk mempermudah melakukan kendali otomatis pada integrated device electronic.Dari data hasil pengujian bahwa prototype ini dapat mengendalikan irigasi proses penyiraman dengan aplikasi android di smartphone, melalui komunikasi integrated device electronic pada jaringan internet diperoleh kondisi rata-rata Tx $46 \mathrm{~m} / \mathrm{s}$ dan Rx $51 \mathrm{~m} / \mathrm{s}$ dan ping 35m/s sampai $120 \mathrm{~m} / \mathrm{s}$, sehingga dengan kondisi koneksi internet tersebut maka proses kendali otomasi penyiraman secara drip dapat dilakukan dengan set nilai sensor YL-69 antara 785-810, NodeMCUesp 8266. Sedangkan kelemahan dari prototype ini yaitu jika kondisi internet sedang tidakstabil maka akan terjadi delay sehingga mempengarui update data sensor YL69 yang terkirim pada smartphone.
\end{abstract}

Kata Kunci: Irigasi tetes, Internet of things, integrated device electronic, nodeMCUesp 8266

ABSTRACT. Increasingly less land for farming or farming, makes urbanites innovate by utilizing land to increase income because of economic needs. Planting activities in narrow areas require attention in the management of land does not need seeds and plant roots must be maintained in the humidity range of $60 \%$. This causes urbanites to have more than one occupational profession while fixing difficulties in time sharing. The process of working and watering is still done manually. So that the irrigation process is not manual, we need a process that can bridge the process of controlling sensors, hardware, software in real time, the concept of technology that utilizes the internet or better known as the internet of things (IoT). The making of this prototype starts from the circuit between the Esp8266 nodeMcU board as the access and processing center, then the relay is connected to the GPIO at the output connected to the motor selenoid pump and the power supply. Furthermore, the YL 69 sensor is opened on the GPIO and 5V GPIO power source, then creates an Android-based interface application to facilitate automatic replacing of the integrated electronic device. internet network obtained an average of Tx $46 \mathrm{~m} / \mathrm{s}$ and Rx $51 \mathrm{~m} / \mathrm{s}$ and ping $35 \mathrm{~m} / \mathrm{s}$ to $120 \mathrm{~m} / \mathrm{s}$, so that with an internet connection the watering automation process can be done by setting the YL-69 sensor value between 785-810, NodeMCUesp 8266. While the weakness of this prototype is that if you use the internet is not stable there will be a delay so that it affects the YL69 sensor data update sent to the smartphone.

Keywords: Drip irrigation, Internet of things, integrated device electronic, nodeMCUesp 8266

\section{PENDAHULUAN}

Semakin berkurangnya lahan perkotaan untuk bercocok tanam atau bertani membuat para kaum urban melakukan inovasi dengan memanfaatkan lahan sempit untuk meningkatkan pendapatan karena tuntutan kebutuhan ekonomi. Aktifitasbercocok tanam dilahan sempit membutuhkan perhatian dalam manajemen irigasi karena unsur kehidupan biji dan akar tanaman harus dijaga kelembapan pada kisaran 60\% (Lutfiyana, Hudallah, \& Suryanto, 2017), selama ini proses bercocok tanamdilahan sempit memiliki permasalahanyaitu pada proses irigasi. Hal ini dikarenakan para kaum urban memiliki lebih dari satu profesi pekerjaan serta mengalami kesulitan dalam membagi waktu. Sehingga prosesirigasi dan penyiraman masih dilakukan secara manual.Agar proses irigasi tidak manual, makadibutuhkan suatupendekatan yang mampu menjembatani proses otomasi melibatkan sensor, hardware, dan perangkat lunak secara real time yaitu suatu konsep teknologi yang memanfaatkan internet atau lebih dikenal internet of things (IoT).

Internet of Things(IoT)adalah konsep yang bertujuan memperluas penggunaan dari koneksi internet yang terhubung secara terus menerus, kemampuan berbagi data, remote dekstop controling, dan machine to 
machine di dunia nyata (Dewi \& Sulaeman, 2018). Contoh IoT yaitu penggunaan sensor yang tersambung ke jaringan lokal dan global yang selalu aktif. Teknologi internet of things (IoT) pada dasarnya dibuat dan dikembangkan oleh manusia untuk mempermudah setiappekerjaan dan urusan dalam berbagai aspek bidang kehidupan. Salah satunya dapat diterapkan dalam bidang pertanian dengan mengintegrasikan otomasi dengan sensor.

Penerapan sentuhan metode teknologi dalam bercocok tanam merupakan suatu carauntuk melakukan budidaya terutama di lahan sempit. Salah satu metodenya yaitu menggunakan teknik hidroponik, umumnya tanaman yang dibudidayakan seperti sawi, pakcoy, dan seledri.Teknik hidroponik di lahan sempit juga dipengaruhi faktor suhu dan kelembapan karena lokasi diperkotaan suhu udara relatif tinggi berkisar $32^{\circ} \mathrm{C}$ $35^{0}$ dengan kelembapan mencapai $85 \%$. Kondisi ini yang menyebabkan proses irigasi perlu pengawasan yang berkelanjutan agar tanaman tidak layu dan tetap segar. Kegiatan ini yang banyak menyita waktu bagi kaum urban, sehingga harus sering bolak balik dari tempat kerja ke rumah untuk memantau tanamannya. Mengatasi hal tersebut maka peneliti membangun prototype sistem yang mampu melakukan irigasi otomatis secaraIntegrated device elektronik dengan kendali IoT melalui smartphone.

Beberapa penelitian yang mendasariyaitu, tentang penerapan irigasi tetes dengan kendali otomatis dengan sensor ultrasonik(Chaer, Abdullah, \& Priyati, 2016) perangkat ini memeiliki kekurangan yaitu belum dapat mengetahui kondisi kelembapan tanah. Riset lainya yang menjadi dasar membangun prototype ini tentang pengaturan debit air irigasi sawah dengan kendali otomatis(Nurfaijah, Setiawan, Arif, \& Widodo, 2018) pengaturan perintah perangkat masih melalui SMs jadi tidak sepenuhnya otomatis. Sedangkan menurut(masykur, 2016)pengelolaan perangkat elektronik yang dikendalikan secara real timemelalui jaringan dapat memberikan banyak kemudahan bagi penggunanya,akan tetapi proses kendali di riset yang dilakukan masih pada koneksi intranet lokal. Pengembangan dilakukan di penelitian(Prasetyo \& Setyawan, 2018)yang berpendapat bahwa pemanfaatan internet selain sebagai media penyampaian data informasi jugadapat mengendalikan perangkat keras atau sensor yang dilakukan dengan integrasi sensor ultrasonik dan telegram sebagai peringatan awal akan terjadinya banjir, hal ini merupakan konsep dari penerapan IoT, tetapi masih memiliki kekurangan karena interface telegram adalah jejaring sosial dan masih membutuhkan bot telegram yang sering terjadi delay pada server protokol SMTP. Internet juga menjadi kunci utama pada IoT menurut (Cobantoro, 2018) IoT ditekankan pada pelayanan Quality of service pada setiap komunikasi data yang dijalankan.

\section{Metode Penelitian}

Pengembangan prototipe diawali beberapa fase berdasarkan riset terdahulu sebagai dasar dimana terdapat rincian bahan serta materi yang dibuat secara sistematis dan logis sehingga dapat dijadikan pedoman dalam menyelesaikan masalah yang ada.

\subsection{Konsep fungsional sistem.}

Pada fase ini diawali dengan membuat desain wiring pada perangkat seperti Gambar 1. Yang terdiri dari rangkaian antara board nodeMcU esp8266 sebagai pusat kendali dan prosesing, kemudian relay terhubung GPIO pada output tersambung motor selenoid pompa dan catu daya. Selanjutnya sensor YL 69 dihubungkan pada GPIO dan catudaya 5V GPIO.

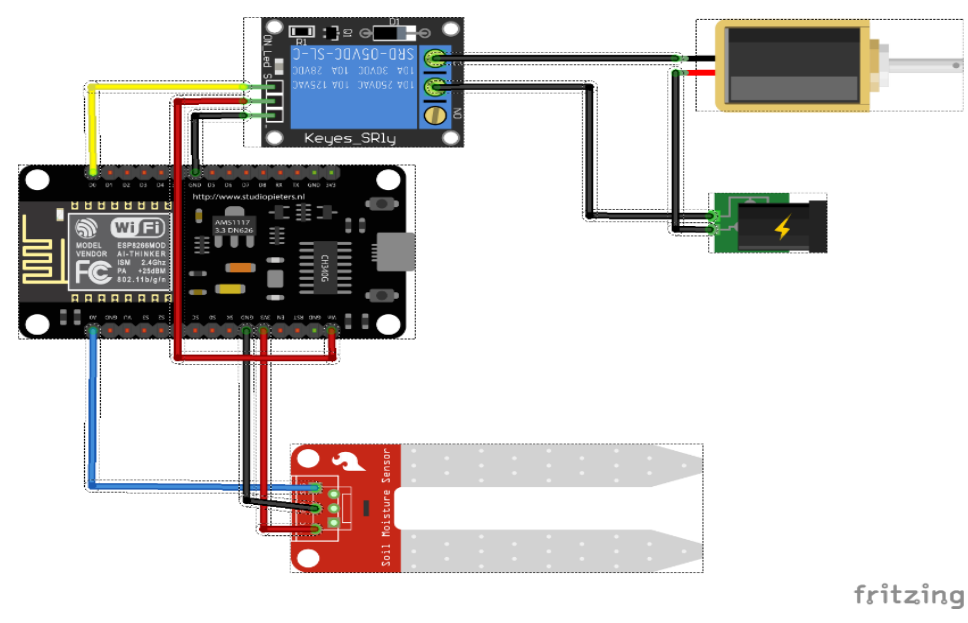

Gambar 1. Desain Wiring perangkat 


\subsection{Perancangan perangkat lunak}

Fase berikutnya adalah membuat perangkat lunak untuk menjalankan rangkaian pada Gambar 1. Terdapat bahasa dua yang digunakan, yang pertama menggunakan bahasa $\mathrm{C}$ bertujuan untuk mengendalikan fungsi otomasi dari sensor YL 69, relay, dan selenoid pompa. Untuk mempermudah compiling pembuatan program menggunakan aplikasi arduino IDE seperti Gambar 2.

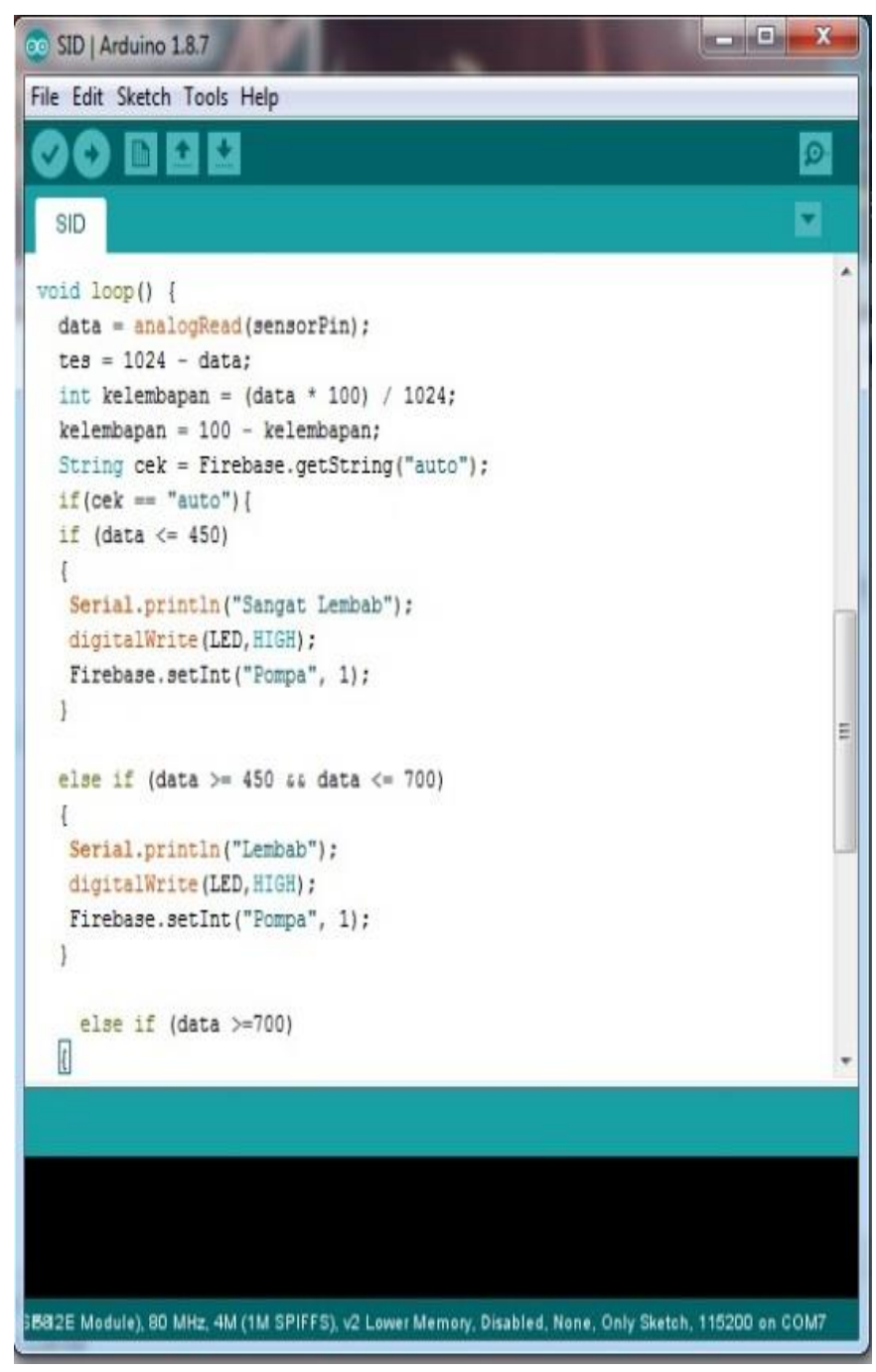

Gambar 2. Proses pembuatan program

Setelah dilakukan compiling proses selanjutnya membuat aplikasi interface antar muka berbasis android untuk mempermudah melakukan kendali otomatis. Agar interface tersinkronisasi perlu dilakukan pengecekan pada Gambar 1. Dengan alur sistematis yang telah dibuat seperti pada Gambar 3. 


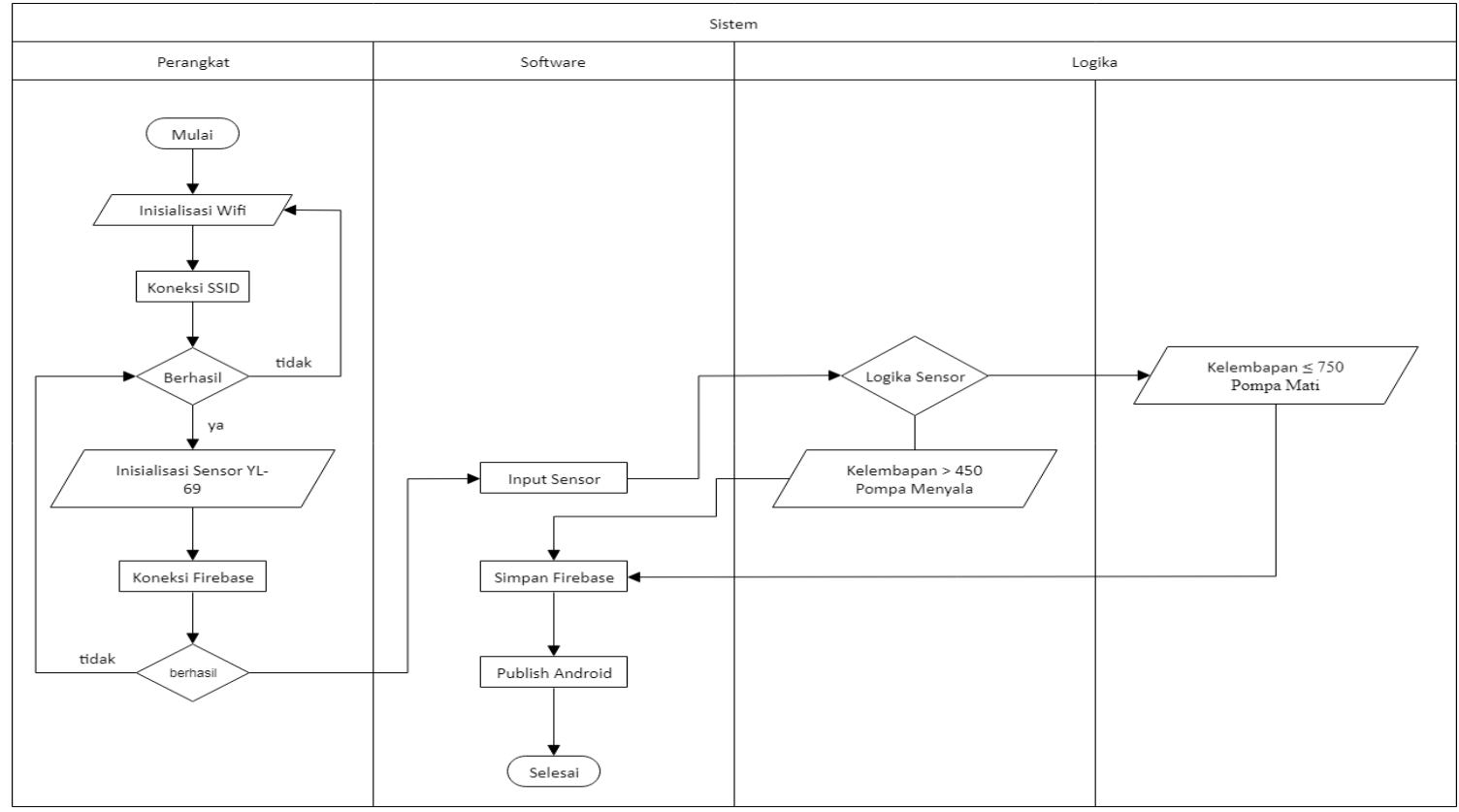

Gambar 3.Flowchart sistemintegrated device electronic

Pengecekan kondisi perintah seperti di Gambar 3. Bertujuan untukmengkalibrasi sensor YL69pada perangkat lunak, ketika perintah else if pada kondisi poin sensor jika >450 maka pompa menyala otomatis saat permukaan kering dan $<750$ pompa mati. Kondisi inilah yang nantinya akan dimunculkan seta dikendalikan melalui interface android seperti pada Gambar 4.

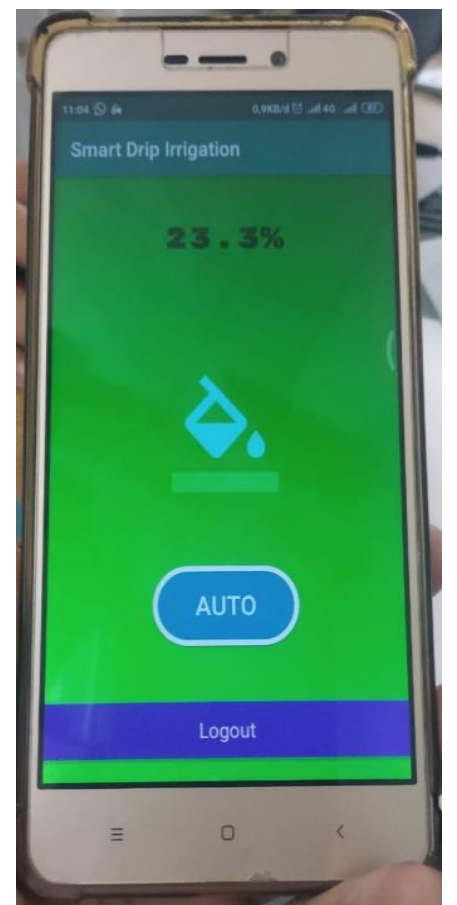

Gambar 4. interface antar muka android

\section{Pembahasan}

Proses pengujian kalibrasi sensor dengan perangkat lunak arduino IDE bertujuan untuk mengetahui respon fungsi otomasi perangkat lunak dan keras, berikut kondisi saat pengujian kalibrasi sensor seperti ditunjukkan pada Tabel 1. 
Tabel 1. Uji Kalibrasi Sensor

\begin{tabular}{cccccc}
\hline No & Nilai sensor & Perintah & \multicolumn{2}{c}{ Output tegangan } & \multirow{2}{*}{ keterangan } \\
\cline { 3 - 5 } & & & relay & Selenoid pump & \\
\hline $\mathbf{1}$ & 791 & Auto & $4,76 \mathrm{~V}$ & $220 \mathrm{~V}$ & Penyiraman ON \\
\hline $\mathbf{2}$ & 520 & Auto & 0 & 0 & Penyiraman Off \\
\hline $\mathbf{3}$ & 480 & Auto & 0 & 0 & Penyiraman Off \\
\hline $\mathbf{4}$ & 808 & Auto & $4,83 \mathrm{~V}$ & $220 \mathrm{~V}$ & Penyiraman ON \\
\hline $\mathbf{5}$ & 790 & Auto & $4,87 \mathrm{~V}$ & $220 \mathrm{~V}$ & Penyiraman ON \\
\hline $\mathbf{6}$ & 785 & Auto & $4,86 \mathrm{~V}$ & $220 \mathrm{~V}$ & Penyiraman ON \\
\hline $\mathbf{7}$ & 810 & Auto & $4,88 \mathrm{~V}$ & $220 \mathrm{~V}$ & Penyiraman ON \\
\hline
\end{tabular}

Proses pengujian berhasil dilakukan dengan hasil, output tegangan yang diukur pada kondisiarus DC Relay 0 V dengan set nilai sensor YL69 antara 480 sampai 520, maka otomasi pompa otomatis berhenti, justru sebaliknya pada kondisi arus DC 4,76 V- 4,87 dengan Set nilai sensor 785-810 kondisi pompa akan menyala dan melakukan penyiraman.

Selanjutnya pengujian konektifitas pada jaringan internet dilakukan untuk mengetahui kecepatan data terkirim dan diterima oleh perangkat integrated device electronik. Pada Tabel 2.

Tabel 2. Uji respon perangkat IDE pada jaringan internet.

\begin{tabular}{cccccc}
\hline $\begin{array}{c}\text { Pengujian } \\
\text { ke- }\end{array}$ & Tx & Rx & $\begin{array}{c}\text { Selenoid } \\
\text { pompa }\end{array}$ & Ping & $\begin{array}{c}\text { Data Tersimpan } \\
\text { firebase }\end{array}$ \\
\hline $\mathbf{1}$ & $20 \mathrm{~m} / \mathrm{s}$ & $25 \mathrm{~m} / \mathrm{s}$ & Auto & $40 \mathrm{~m} / \mathrm{s}$ & tersimpan \\
$\mathbf{2}$ & $40 \mathrm{~m} / \mathrm{s}$ & $53 \mathrm{~m} / \mathrm{s}$ & Auto & $80 \mathrm{~m} / \mathrm{s}$ & tersimpan \\
$\mathbf{3}$ & $60 \mathrm{~m} / \mathrm{s}$ & $64 \mathrm{~m} / \mathrm{s}$ & Auto & $120 \mathrm{~m} / \mathrm{s}$ & tersimpan \\
$\mathbf{4}$ & $68 \mathrm{~m} / \mathrm{s}$ & $68 \mathrm{~m} / \mathrm{s}$ & Auto & $70 \mathrm{~m} / \mathrm{s}$ & tersimpan \\
$\mathbf{5}$ & $28 \mathrm{~m} / \mathrm{s}$ & $33 \mathrm{~m} / \mathrm{s}$ & Auto & $35 \mathrm{~m} / \mathrm{s}$ & tersimpan \\
$\mathbf{6}$ & $40 \mathrm{~m} / \mathrm{s}$ & $43 \mathrm{~m} / \mathrm{s}$ & Auto & $50 \mathrm{~m} / \mathrm{s}$ & tersimpan \\
$\mathbf{7}$ & $67 \mathrm{~m} / \mathrm{s}$ & $70 \mathrm{~m} / \mathrm{s}$ & Auto & $72 \mathrm{~m} / \mathrm{s}$ & tersimpan \\
Rata-rata & $46 \mathrm{~m} / \mathrm{s}$ & $51 \mathrm{~m} / \mathrm{s}$ & & & \\
\hline
\end{tabular}

Hasil pengujian pada Tabel 2. Bahwa kondisi otomasi pompa secara otomatis dengan sensor YL69 dan dihubungkan dengan jaringan internet maka diperoleh, rata-rata data Tx 46 m/s dan Rx $51 \mathrm{~m} / \mathrm{s}$ secara real time pada nodeMCUesp 8266, sehingga proses pengendalian relay dan pompa dengan kisaran ping $35 \mathrm{~m} / \mathrm{s}$ sampai $120 \mathrm{~m} / \mathrm{s}$ masih mampu mengirimkan log data pada google firebase seperti pada Gambar 5 . 


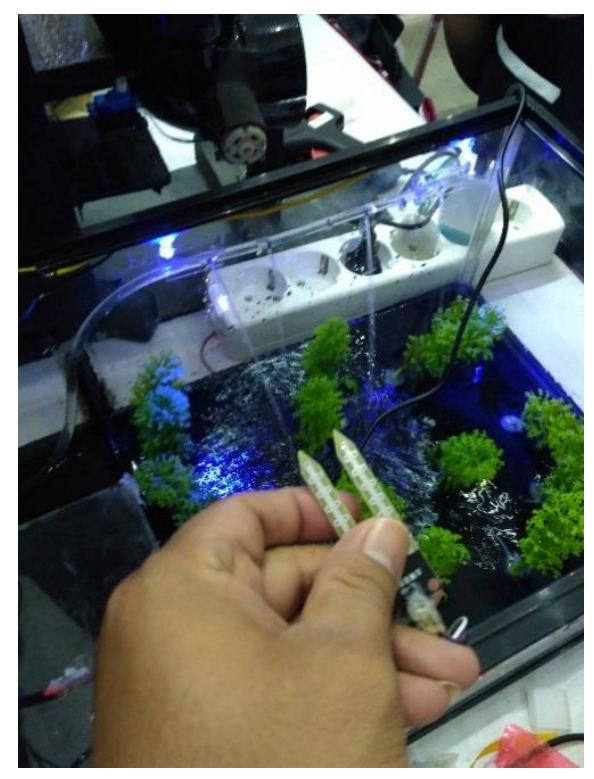

Gambar 5. uji respon perangkat $I D E$

Hasil proses pengujian penelitian ini, bahwa pembaharuan dari riset terdahulu yaitu purwarupa perangkat IDE ini dapat digunakan pada kondisi jaringan internet yang kondisi ping nya tidak terlalu bagus, mempermudah monitoring dan kendali melalui smartphone yang dibangun dengan android studio. Manfaat lainnya perangkat ini merupakan solusi untuk tata kelola pengairan di lahan tandus atau musim kemarau.

\section{Kesimpulan}

Beberapa percobaan telah dilakukan dan disimpulkan, Dari data hasil pengujian bahwa prototype ini dapat mengendalikan irigasi proses penyiraman dengan aplikasi android di smartphone, melalui komunikasi integrated device electronicpada jaringan internet diperoleh kondisi rata-rata Tx $46 \mathrm{~m} / \mathrm{s}$ dan $\mathrm{Rx} 51 \mathrm{~m} / \mathrm{s}$ dan ping $35 \mathrm{~m} / \mathrm{s}$ sampai $120 \mathrm{~m} / \mathrm{s}$, sehingga dengan kondisi koneksi internet tersebut maka proses kendali otomasi penyiraman secara drip dapat dilakukan dengan set nilai sensor YL-69 antara 785-810, NodeMCUesp 8266. Sedangkan kelemahan dari prototype ini yaitu jika kondisi internet sedang tidak stabil maka akan terjadi delay sehingga mempengarui update data sensor YL69 yang terkirim pada smartphone.

\section{DAFTAR RUJUKAN}

Chaer, M. S. I., Abdullah, S. H., \& Priyati, A. (2016). Aplikasi Mikrokontroler Arduino Pada Sistem Irigasi Tetes Untuk Tanaman Sawi (Brassica Juncea) (Application of Arduino Microcontroller on Drip Irrigation for Mustard Plant (Brassica juncea). Jurnal Ilmiah Rekayasa Pertanian Dan Biosistem, 4(2), 228-238. Retrieved from https://jrpb.unram.ac.id/index.php/jrpb/article/view/28

Cobantoro, A. F. (2018). ANALISA QoS (QUALITY OF SERVICE) PADA JARINGAN RT-RW NET DENGAN KENDALI RASPBERRY PI. Network Engineering Research Operation, 4(1). https://doi.org/10.21107/nero.v4i1.109

Dewi, K., \& Sulaeman, S. (2018). PENERAPAN TEKNOLOGI INTEGRATED DEVICE ELECTRONIC (IDE) UNTUK PENINGKATAN PRODUKTIFITAS HASIL PERTANIAN PADA PURWARUPA KUMBUNG JAMUR TIRAM DI DATARAN RENDAH. Seminar Nasional Hasil Penelitian (SNP2M $P N U P), O(0)$. Retrieved from http://jurnal.poliupg.ac.id/index.php/snp/article/view/784/0

Lutfiyana, L., Hudallah, N., \& Suryanto, A. (2017). Jurnal Teknik Elektro. In Jurnal Teknik Elektro (Vol. 9). Retrieved from https://journal.unnes.ac.id/nju/index.php/jte/article/view/11087

masykur, fauzan. (2016). APLIKASI RUMAH PINTAR (SMART HOME) PENGENDALI PERALATAN ELEKTRONIK RUMAH TANGGA BERBASIS WEB. Jurnal Sains Dan Teknologi Industri, 14(1), 93-100. Retrieved from http://ejournal.uin-suska.ac.id/index.php/sitekin/article/view/2185

Nurfaijah, -, Setiawan, B. I., Arif, C., \& Widodo, S. (2018). Sistem Kontrol Tinggi Muka Air Untuk Budidaya Padi. Jurnal Irigasi, 10(2). https://doi.org/10.31028/ji.v10.i2.97-110

Prasetyo, A., \& Setyawan, M. B. (2018). PURWARUPA INTERNET OF THINGS SISTEM KEWASPADAAN BANJIR DENGAN KENDALI RASPBERRY PI. Network Engineering Research Operation, 3(3). https://doi.org/10.21107/NERO.V3I3.97 
